\title{
A new model of dynamic of plant biodiversity in changing farmlands: Implications for the management of plant biodiversity along differential environmental gradient in the Yellow River of Henan Province in the spring
}

\author{
Bing-Hua Liao \\ ${ }^{1}$ The Key Laboratory of Ecological Restoration in Hilly Areas, Forestry Department of Henan Province, Ping-ding-shan \\ University, Ping-ding-shan, Henan Province 467000, China. \\ ${ }^{2}$ Department of Environment and Geography, Ping-ding-shan, Henan Province 467000, China. \\ ${ }^{3}$ Institute of Ecological Science and Technology, College of Life Sciences, Henan University, Kaifeng 475001, China.
}

Received 05 July, 2011; Accepted 26 February, 2014

\begin{abstract}
The intermediate disturbance hypothesis (IDH) is often used as a model or investigating the linkages between disturbance intensity and biodiversity. However, the relationship between plant diversity and disturbance gradient makes it difficult to compare data from different researches and draw general models. It is importance to assess the relationship between disturbance gradients and herbaceous species diversity in the farmland center/farmland ridge/farmland boundary on varying spatial scales along the Yellow River watershed ecosystem of Henan Province in the arctic. Using community ecology techniques and quantitative measurements of disturbance, results show a linear relationship between weighted values of disturbance intensity and herbs species diversity (Shannon index), which were significantly, negatively correlated $(P<0.01)$ in the differential ecosystem types (farmland center/farmlandridge/farmland boundary) along differential disturbance gradient. Thus, understanding a linear relationship between herbs diversity dynamics and disturbance gradient in the differential type's landscapes is important for further research of local ecosystem functions and the goal of agricultural sustainable development in the context of biodiversity conservation. These results indicated that a synthesis quantitative index of disturbance (e.g. weighting values of disturbance) is the most essential environmental factors affecting herbs species diversity in the ecosystem to building a model. Therefore, this model plays a vital part in conserving global biodiversity and maintaining global ecosystem function.
\end{abstract}

Key words: Model, herbs species diversity, disturbance gradient, significantly, the Yellow River.

\section{INTRODUCTION}

Ecological model of the relationship between species diversity and environment is important along environment gradient (Boyd, 2012; Liao and Wang, 2010; Keeling et al., 2000). Ecosystems are composed of large numbers 
Table 1a. The relationship between IDH and biodiversity from the different perspectives.

\begin{tabular}{|c|c|}
\hline The relationship between IDH and biodiversity from the different perspectives & Author \\
\hline Water level fluctuations, fire and grazing are essential for maintaining plant diversity. & Keddy (2005) \\
\hline Increased diversity at intermediate disturbance was due primarily to increased evenness. & Aronson and Precht, (1995) \\
\hline Diversity and soil properties were best at intermediate disturbance levels. & Zhang et al. (2010) \\
\hline The IDH pattern was obtained for low frequency dependence and low immigration. & Cordonnier et al. (2006) \\
\hline $\begin{array}{l}\text { Generate a period-bubbling bifurcation structure and population dynamics that are most } \\
\text { variable at intermediate disturbance frequencies. }\end{array}$ & Reluga (2004) \\
\hline
\end{tabular}

Table 1b. The physical geographic conditions of the Yellow River basin nature reserve.

\begin{tabular}{|c|c|c|c|c|}
\hline Precipitation $(\mathrm{mm})$ & Annual mean temperature $\left({ }^{\circ} \mathrm{C}\right)$ & Latitude ( ()$\left.^{\circ}\right):$ & Longitude $(\stackrel{\circ}{)})$ & Elevation $(\mathrm{m}) \dagger$ \\
\hline $800-1100$ & $12.4-14.8$ & $34.58-36.07$ & $116.06-110.41$ & $34-412$ \\
\hline
\end{tabular}

†Above sea level.

of plant species along environmental gradient, making species-centered studies of systemic processes and functions extremely difficult, if not out rightly impossible to carry out (Liao et al., 2011a, b). The intermediate disturbance hypothesis (IDH) suggests that species diversity will be maximal at intermediate levels of disturbance (Connell, 1978). Moreover, many experiments have assessed the relationship between plant species diversity and disturbance intensity from IDH perspective along different disturbance gradients in theoretical ecology (Leis et al., 2005). For example, Leis et al. (2005) found that disturbance up to intermediate levels can be used to maintain biodiversity by enriching the plant species pool. Further, Biswas and Mallik (2010) suggest that plant species richness and diversity, functional richness and diversity reached peaks at moderate disturbance intensity in riparian and upland plant communities.

Therefore, the relationship between plant species diversity and intermediate disturbance intensity has many real world applications in the field of ecological conservation and restoration (Table 1a).

Here, using plant community ecology techniques, this study investigated three key questions regarding the relationship between herbaceous plants species diversity and intermediate disturbance levels in the ecosystem types (e.g. farmland center, farmland ridge/farmland boundary, etc.). First, this study asked if the relationship between herbaceous species diversity dynamics and disturbance gradient from IDH perspective can be compressed into a general model that is universally applicable to ecosystem studies. Therefore, this study shows how to link herbaceous species diversity and disturbance along disturbance gradient and can be applied to real world scenarios in order to prevent biodiversity loss and help in the management of degrading or degraded ecosystems.

\section{MATERIALS AND METHODS}

The dynamics of plant diversity in Henan Province section of the Yellow River basin are the results of the historical natural and anthropogenic activities (Table 1b, Figure 1).

Quantitative assessments mainly depended on disturbance of human-driven and season driven changes in herbaceousdiversity and were based on a careful choice of landscape dynamics (Table 2).

Using community ecology techniques, we examined the influences of different disturbances on dynamics of herbaceous species diversity and disturbance interactions along the different environmental gradients in the Yellow River in the Henan Province from May 2010 to January 2011. Thirteen plots were established per 10 $\mathrm{km}$ length. A total of 30 plots were set. Each study plot, consisted of one $20 \times 20 \mathrm{~m}$ tree layer plot, five (the center and four corners of the study plot) $2 \times 2 \mathrm{~m}$ shrub layer quadrates and five $1 \times 1 \mathrm{~m}$ herbaceous layer quadrates. Thus, these plots include 150 herbaceous layer quadrates in the farmland center, 150 herbaceous layer quadrates in the farmland boundary, and 150 herbaceous layer quadrates in the ridge of farmland from May 2010 to January 2011 (Table 3).

\section{Traditional indices}

These are the most widely used indices: Shannon index (Margalef, 1958); Shannon index of diversity is generally calculated as the 


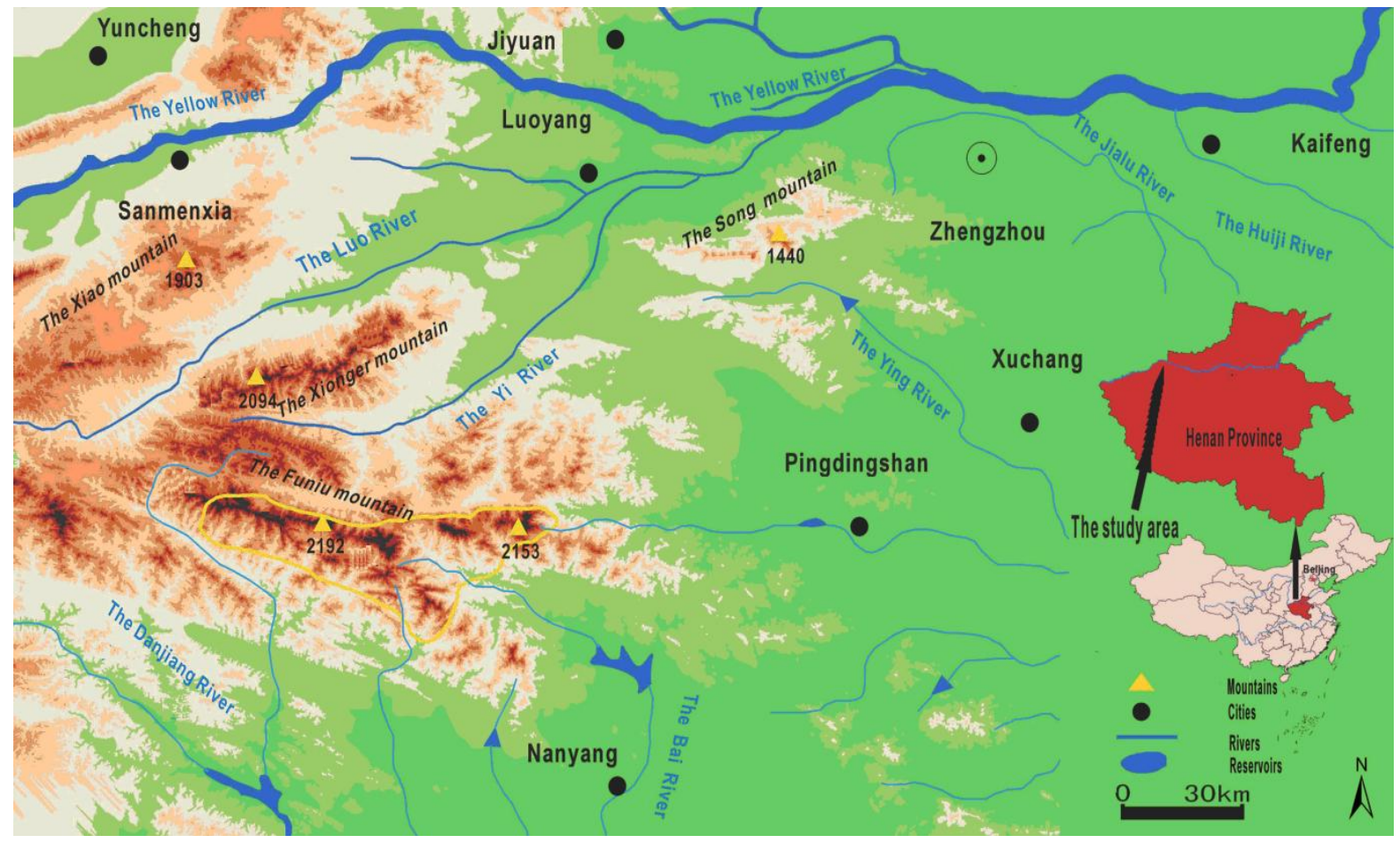

Figure 1. A digital cadastre map in the Yellow River of Henan Province.

Table 2. The selection of the weighting values of disturbance.

\begin{tabular}{ll}
\hline $\begin{array}{l}\text { Quantitative measurements of disturbance to select and identify } \\
\text { different disturbance }\end{array}$ & $\begin{array}{l}\text { Differential agro-ecosystem } \\
\text { types }\end{array}$ \\
\hline $\begin{array}{l}\text { Values of weighting of disturbance=Usage amount of herbicide } \\
+100 / \text { Return interval of using herbicide }\end{array}$ & $\begin{array}{l}\text { Farmland center } \\
\text { Farmland ridge }\end{array}$ \\
$+100 /$ Return interval of tillage & Farmland boundary \\
\hline
\end{tabular}

Table 3. Investigation index along the elevation gradient variable.

\begin{tabular}{lllllll}
\hline Investigation & Layer & Community & Species & Height & Crow & Diameter \\
\hline Community & Tree/shrub & Coverage & Species/ individual & Layer's & Crow height/ & Basal \\
Investigation & /herbaceous & /community's age structure & number & Height & width & diameter \\
\hline
\end{tabular}

complement of $\mathrm{H}: H^{\prime}=-\Sigma p_{\mathrm{i}} \log \left(p_{\mathrm{i}}\right)$. Where $\mathrm{i}$ is the number of species and $p_{i}$ is the proportion of the sample belonging to the $i$ th species.

\section{RESULTS}

Disturbance is an important environmental factor affecting weed species diversity in anthropogenic activities in the farmland center/the farmland ridge areas/the farmland boundary areas. The relationship between values of weighing disturbance and the weed species diversity investigated vary significantly in the herbaceous layer along the environmental gradient on varying disturbance scales in the different disturbance intensity farmland (Figures 2 to 4 ).

These results which shows that herb diversity (e.g. Shannon index) is expected to increase when weighting values of disturbance is reduced along disturbance gradients in the farmland areas of the Yellow River in the 


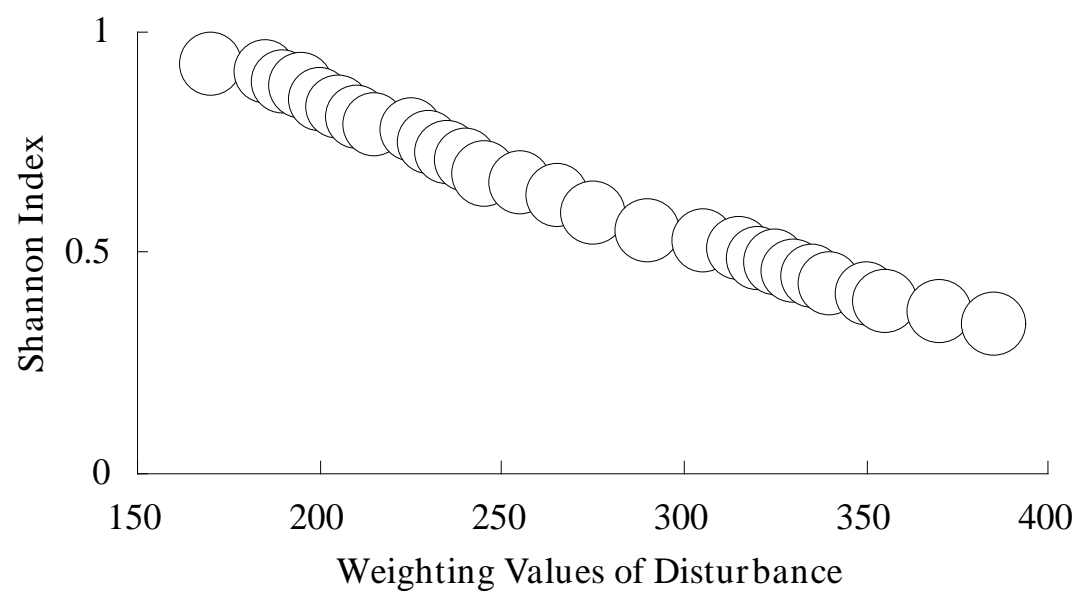

Figure 2. The relationship between Shannon index and disturbance in the farmland center areas.

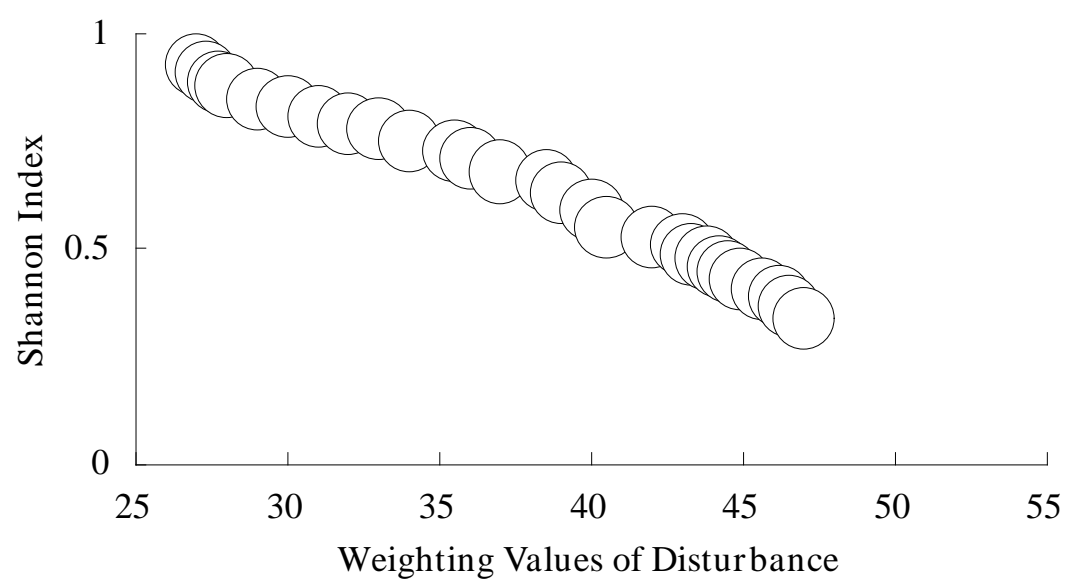

Figure 3. The relationship between Shannon index and disturbance in the farmland boundary areas.

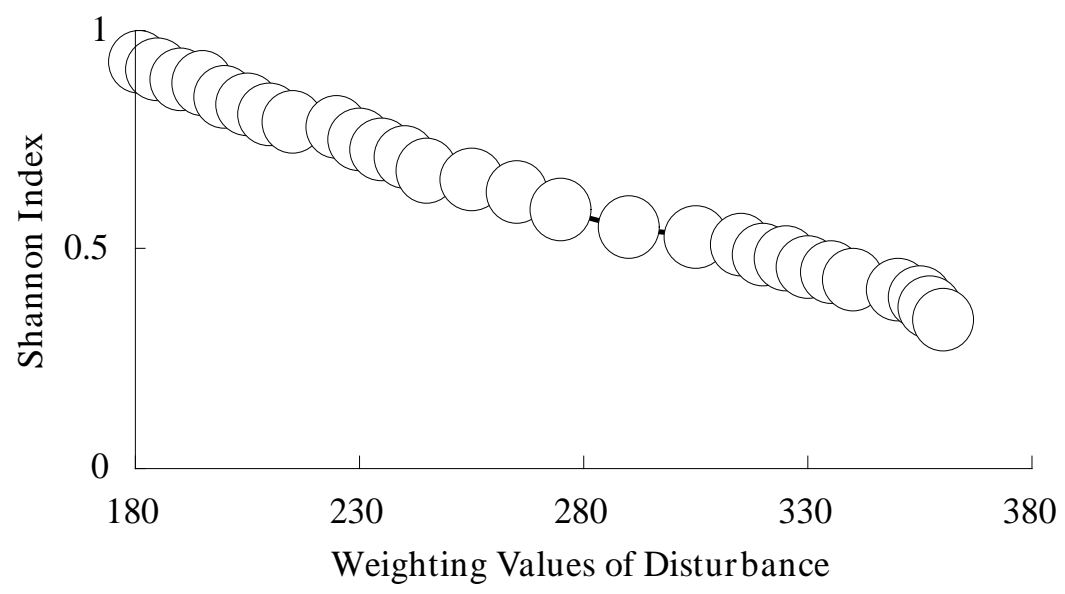

Figure 4. The relationship between Shannon index and disturbance in the farmland ridge. 
Table 4. The negative correlation between Shannon index and weighting values of disturbance.

\begin{tabular}{lc}
\hline Differential ecosystem types & Shannon index \\
\hline Farmland center & $-0.974^{* *}$ \\
Farmland ridge & $-0.983^{* *}$ \\
Farmland boundary & $-0.989^{* *}$ \\
\hline
\end{tabular}

Henan Province (Figures 2 to 4). Secondly, herbaceous diversity (e.g. Shannon index) is expected to decrease when weighting values of disturbance is increased along disturbance gradients in the farmland. Thus, our result implies that weak disturbance should lead to higher herbs diversity in the farmland.

These results suggest that herb species diversity (e.g. Shannon indicator) is expected to increase when weighting values of disturbance is reduced along disturbance gradients in the farmland boundary areas and the ridge of farmland of the Yellow River in the Henan Province (Figures 3 and 4). In addition, herb species diversity is expected to decrease when weighting values of disturbance is increased along disturbance gradients in the farmland boundary areas and the ridge of farmland (Figures 3 and 4). Therefore, this result implies that weak disturbance should lead to higher herbs species diversity in the farmland boundary areas. However, is there relationship between the species biodiversity and disturbance gradient in the Yellow River of Henan Province? To show this, the correlation between species biodiversity and the weighting values of disturbance was then analyzed (Table 4).

This results suggest a linear relationship between weighting values of disturbance and herb species diversity (Shannon index), which were significantly, negatively correlated $(P<0.01)$. The results indicated that disturbance, largely determined by values of weighting of disturbance, are the most important environmental factors affecting herb species diversity (Table 4).

\section{A general model of the links between herbs diversity and disturbance gradient from IDH perspective}

The IDH is used as a framework for investigating the linkages between disturbance and species diversity. Unfortunately, the various IDH makes it difficult to compare data from different studies in order to draw general conclusions (Connell, 1978). It is therefore important to develop the model which is universally applicable across a range of agro-ecosystems so that the relationship between herbaceous species diversity and disturbance gradient can be more accurately quantified with quantitative measurements of disturbance intensity. Here, we proposed the use of model framework that incorporates model (Figures 2 to 5) operating on varying spatial-temporal and disturbance scales for in-depth studies of the relationship between herbs species diversity and disturbance gradient (e.g. anthropogenic disturbance and natural disturbance) (Figures 5).

The model can help identify the relationship between herbaceous species diversity and disturbance intensity most relevant to tolerating environmental fluctuations or recovering from IDH perspective (Figure 5). The model is useful for ecosystem sustainable development in the context of biodiversity conservation. For example, Bartels and Chen (2010) explained that whether resource quantity or resource heterogeneity is the determinant of under story plant diversity in individual studies, was dependent on stand succession stage(s), presence or absence of intermediate disturbance, and forest biome within which the studies were conducted. Carvalheiro et al. (2011) suggest that presence of weeds allowed pollinators to persist within sunflower fields, maximizing the benefits of the remaining patches of natural habitat to productivity of this large-scale crop.

\section{Applying general model to species conservation and ecosystem management}

The model can use more theoretical ecology (e.g. diversity dynamics, species composition, food web structure, diversifying plant-microbial system, ecosystem stability/functioning, organic agriculture, biodiversity law, watershed ecosystem management, assessment of ecosystems and biodiversity, scale dependence) (Stutter et al., 2009; Shennan, 2008; Menalled et al., 2001, Bartels and Chen, 2010; Crowder et al., 2010; Bai et al., 2004; Davis et al., 2007; Bernez et al., 2002; Marris, 2010; Crawley and Harral, 2001). For instance, Menalled et al. (2001) suggested that agricultural management systems can have both immediate and long-term effects on weed species density, abundance and diversity. Shennan (2008) proposed that important elements for understanding biotic interactions include consideration of the effects of diversity, species composition and food web structure on ecosystem processes; the impacts of timing, frequency and intensity of disturbance; and the importance of multitrophic interactions in agroecosystem. Stutter et al. (2009) proposed a mechanism whereby the establishment of vegetated buffer strips between cropland and watercourses on previous agricultural land causes a diversifying plant-microbial system. Bartels and Chen (2010) explained that whether resource quantity or resource heterogeneity is the determinant of under-story plant diversity in individual studies was dependent on stand succession stage(s), presence or absence of intermediate disturbance, and forest biome within which the studies were conducted.

Therefore, it will nonetheless be a substantial challenge 


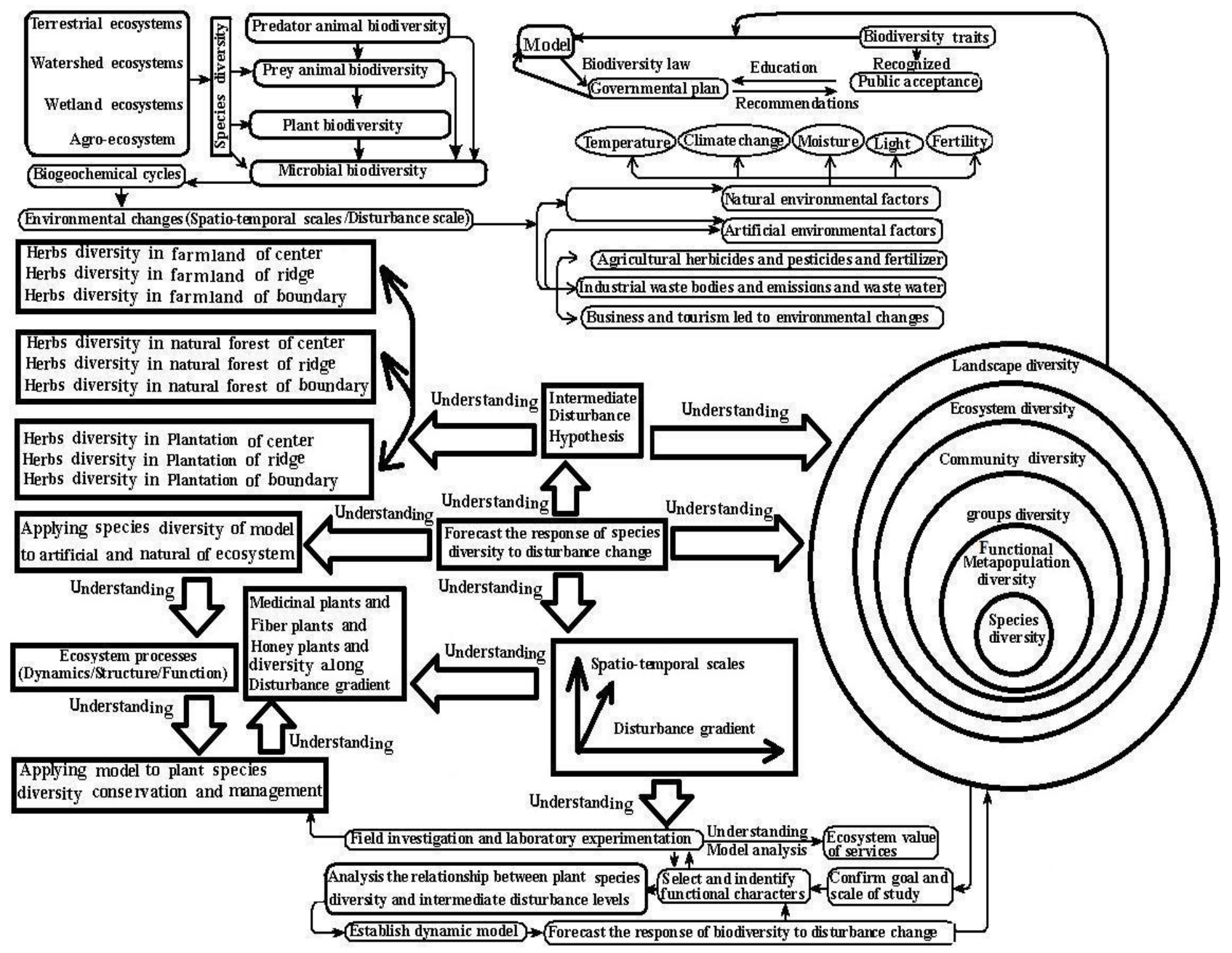

Figure 5. The proposed framework of relationship between herbs species diversity and disturbance gradient that incorporates herbs species diversity dynamic from the intermediate disturbance level, and operating on varying spatial-temporal and disturbance scales. The model was based on some studies (Liao and Wang, 2010; Liao et al., 2011a, b).

to apply this model to specific real world policy problems (Gilbert, 2010; James and Vorhies, 2010; Marris, 2010).

\section{Conclusion}

Progress in three key areas will substantially increase efforts to gain a rigorous understanding on how the links between herbaceous species diversity (Shannon index) and disturbance intensity, and their interactions, influence the response of ecosystem properties to changing biodiversity. First, better understanding of the relationship between herbaceous species diversity and disturbance intensity is correlated, particularly with respect to the predominant forces of human activities. Secondly, the model based on both field investigation of community ecology techniques of 450 herbs layer quadrates and scientific analysis, can use more and more theoretical ecology. Finally, the model can be useful in understanding the plant species diversity and disturbance intensity from IDH perspective. Understanding the model is essential for further research of local ecosystem functions and the goal of agricultural sustainable development in the context of herbs biodiversity conservation in natural or artificial disturbance ecosystem. Therefore, the model may help to ameliorate this situation of losses of plant species diversity (e.g. medicinal plants, honey plants, fiber plants, etc.). 


\section{Future work}

The watershed ecosystems are results of the historical, natural and anthropogenic activities along differential environmental gradient in the Yellow River of Henan Province. However, there is an important question in the future: what are the change patterns for watershed landscape, habitat and biodiversity in the region.

\section{Conflict of Interests}

The author(s) have not declared any conflict of interests.

\section{ACKNOWLEDGEMENTS}

This work was supported by the Forestry Department of Henan Province Science Foundation of China (No.201004044), the National Natural Science Foundation of China (No.41071118), Henan Province Educational Foundation of China (No.12B180022), Ping-Ding-Shan City Societal Science Foundation of China (No.454) and the ideas of some researchers of "1st Biotechnology World Congress" is appreciated.

\section{REFERENCES}

Aronson RB, Precht WF (1995). Landscape patterns of reef coral diversity: a test of the intermediate disturbance hypothesis. J. Exp. Mar. Biol. Ecol. 192(1):1-14.

Bai YF, Han XG, Wu JG, Chuo ZZ, Li LH (2004). Ecosystem stability and compensatory effects in the Inner Mongolia grassland. Nature 431:181-184.

Bartels SF, Chen HY (2010). Is understory plant species diversity driven by resource quantity or resource heterogeneity? Ecology 91(7):19311938.

Bernez I, Haury J, Ferreira MT (2002). Downstream effects of a hydroelectric reservoir on aquatic plant assemblages. Sci. World J. 2:740-750

Biswas SR, Mallik AU (2010). Disturbance effects on species diversity and functional diversity in riparian and upland plant communities. Ecology 91(1):28-35.

Boyd IL (2012). Ecology The Art of Ecological Modeling. Science 337(6092):306-307.

Carvalheiro LG, Veldtman R, Shenkute AG, Tesfay GB, Pirk CW Donaldson JS, Nicolson SW (2011). Natural and within-farmland biodiversity enhances crop productivity. Ecol. Lett. 14(3):251-259.

Connell JH (1978). Diversity in tropical rain forests and coral reefs. Science 199:(4335):1302-1310.

Cordonnier T, Courbaud B, Franc A (2006). The effect of colonization and competition processes on the relation between disturbance and diversity in plant communities. J. Theor. Biodivers. 243(1):1-12.

Crawley MJ, Harral JE (2001). Scale Dependence in Plant Biodiversity. Science 291:864-868.
Crowder DW, Northfield TD, Strand MR, Snyder WE (2010). Organic agriculture promotes evenness and natural pest control. Nature 466:109-112.

Davis SR, Brown AG, Dinnin MH (2007). Floodplain connectivity, disturbance and change: a palaeoentomologi -cal investigation of floodplain ecology from south-west England. J. Anim. Ecol. 76(2):276-288.

Gilbert N (2010). Biodiveristy law counld stymie reserch. Nature 463: 598.

James AN, Vorhies F (2010). Green development credits to forest global biodiversity. Nature 465:869.

Keddy P (2005). Putting the plants back into plant ecology: six pragmatic models for understanding and conserving plant diversity. Ann. Bot. 96(2):177-189.

Keeling MJ, Wilson HB, Pacala SW. (2000). Reinterpreting Space, Time Lags, and Functional Responses in Ecological Models. Science 290(5497):1758-1761.

Leis SA, Engle DM, Leslie DM Jr, Fehmi JS (2005). Effects of short- and long-term disturbance resulting from military maneuvers on vegetation and soils in a mixed prairie area. Environ. Manage. 36(6):849-861.

Liao BH, Ding SY, Liang GF, Guo YL Tian L, Shu S, Zhang Y, Hu HX (2011a). Dynamics of plant functional groups composition along environmental gradients in the typical area of Yi-Luo River watershed. Afr. J. Biotechnol. 10(65):14485-14492.

Liao BH, Ding SY, Liang GF, Hu N, Gu YF, Lu XL, Liang GF, Liu J, Fan YL, Zhai YJ, Ding SP, Ding S (2011b). Dynamics of plant functional groups composition along environmental gradients in the typical area of Yi-Luo River watershed. Afr. J. Biotechnol.10(82): 18939-18947.

Liao $\mathrm{BH}$, Wang $\mathrm{XH}$ (2010). Plant functional group classifications and a generalized hierarchical framework of plant functional traits. Afr. J. Biotechnol. 9(54):9208-9213

Margalef RD (1958). Information Theory in Ecology. General Systems pp. 36-71.

Marris E (2010). UN body will assess ecosystems and biodiversity. Nature 465:859.

Menalled FD, Gross KL, Mark H (2001). Weed aboveground and seedbank community responses to agricultural management systems. Ecol. Appl. 11:1586-1601.

Reluga TC (2004). Analysis of periodic growth-disturbance models. Theor. Popul. Biol. 66(2):151-161.

Shennan C (2008). Biotic interactions, ecological knowledge and agriculture. Philos. Trans. R. Soc. Lond. B Biol. Sci. 363(1492):717739.

Stutter MI, Langan SJ, Lumsdon DG (2009). Vegetated buffer strips can lead to increased release of phosphorus to waters: a biogeochemical assessment of the mechanisms. Environ. Sci. Technol. 43(6):18581863.

Zhang C, Xie G, Fan S, Zhen L (2010). Variation in vegetation structure and soil properties, and the relation between understory plants and environmental variables under different Phyllostachys pubescens forests in southeastern China. Environ. Manage. 45(4):779-792. 